\title{
Use of Diabetes-Related Applications and Digital Health Tools by People With Diabetes and Their Health Care Providers
}

Kacie Doyle-Delgado and James J. Chamberlain

The proliferation of smartphones over the past decade has led to the development of a seemingly endless number of digital applications (apps) designed to improve users' health and fitness. This article addresses the regulation of these apps and provides details about the apps most commonly used by patients in the primary care and diabetes settings. Those described in detail include the American Diabetes Association's Standards of Care app, apps for blood glucose monitoring and tracking and continuous glucose monitoring, lifestyle apps, a glucagon use app, prescription cost-saving apps, and apps for do-it-yourself automated insulin delivery.

The first Apple iPhone was released in June 2007, and the Apple App Store became available 1 year later, offering 500 applications (apps). Worldwide, $>3$ billion people now have smartphones ( 1 ), and $\sim 500$ million people are using mobile apps for diet, exercise, and chronic disease management (2). In 2019, there were 2.2 million apps available for Apple's iOS operating system and 2.6 million for Android smartphones (3), with $>2$ billion app downloads (4). Consumers worldwide spent $\$ 120$ billion on apps in 2019, including $\$ 1.5$ billion on health and fitness apps, which was up $130 \%$ from 2017. One health app (Fitbit) was the sixth most downloaded app in the United States in 2019. There are now $>40,000$ health care apps available online from both the App Store and Google Play $(5,6)$.

The term mobile health (mHealth) seems to have first been used by Robert Istepanian in 2005, who described "emerging mobile communications and network technologies for health care" (7). With the explosion of health and fitness apps and their rapid increase in use worldwide, the World Health Organization (WHO) decided to publish a statement in 2011 to better define mHealth technologies. The WHO adopted the mHealth definition used by the Global Observatory for eHealth in its worldwide survey on electronic health: "medical and public health practice supported by mobile devices, such as mobile phones, patient monitoring devices, personal digital assistants . . . and other wireless devices" (8).

This year, the European Association for the Study of Diabetes and the American Diabetes Association (ADA) jointly published a consensus report on diabetes digital app technology (9). Their report focuses on the role of regulation in diabetes digital health apps, the accuracy of and clinical validation of diabetes apps, data on the safety and efficacy of diabetes apps, and recommendations to help resolve some of the deficiencies in the diabetes health app space.

Diabetes apps focus on one or more diabetes selfmanagement tasks such as blood glucose monitoring, medication or insulin dosing, obtaining diabetes or general health education, and tracking nutrition or physical activity. The Association of Diabetes Care \& Education Specialists provides an app review library (DANAapps.org) as part of its technology initiative. This resource offers reviews from an independent organization, DHX Laboratories, which assesses apps on their security and privacy, operability, usability, functionality, performance, data management capabilities, and the quality of the behavior science behind the app. Quantitative trust scores with direct links for app download are available through this platform. The data-sharing capabilities of apps focused on glucose data may provide further insight in diabetes management, providing health

St. Mark's Hospital and St. Mark's Diabetes Center, Salt Lake City, UT

Corresponding author: James J. Chamberlain, jimchammd@yahoo.com

The publication of this special-topic issue of Clinical Diabetes was supported by unrestricted educational grants to the American Diabetes Association from Abbott Diabetes Care and Dexcom.

https://doi.org/10.2337/cd20-0046

(c)2020 by the American Diabetes Association. Readers may use this article as long as the work is properly cited, the use is educational and not for profit, and the work is not altered. More information is available at https://www.diabetesjournals.org/content/license. 
care providers (HCPs) with an easy way to visualize patterns to inform medication adjustments. Information on the most widely used diabetes apps is provided below (10).

\section{Regulation}

The European Medicines Agency (EMA) and the U.S. Food and Drug Administration (FDA) are responsible for pharmaceutical regulations for traditional health products and software. In the European Union, the European Commission regulates medical devices under the standards set by the E.U. Medical Devices Directive, and each member country maintains its national pharmaceutical regulatory authority. The EMA classifies mobile apps as medical devices if they are used "specifically for diagnostic and/or therapeutic purposes." These apps include those used for diagnosing, preventing, monitoring, and alleviating or treating disease (11). Devices that meet the standards set by the Medical Device Regulation policy standards (more recent guidelines that expand those in the Medical Device Directive) are given the CE (Conformité Européene) mark. This process has generally had fewer obstacles compared with the device approval process of the FDA (12).

In the United States, the FDA regulates medical devices and pharmaceuticals, including some medical mobile apps. Higher-risk apps such as those that calculate insulin dosing are regulated by the FDA, whereas low-risk medical apps that offer only diabetes support and health tracking are not regulated (13). Digital therapeutics, or digiceuticals, are clinically validated health technologies intended to treat a medical or psychological condition, with a focus on improving clinical outcomes. These apps require regulatory approval from the FDA similar to prescription drugs (14). The FDA published a Digital Health Innovation Action Plan with the goals of providing clarity on medical software, launching a precertification program for digital health technology oversight (referred to as the "FDA Pre-Cert for Software"), and building agency expertise. This action plan program offers a pathway for the development and potential approval of safe and effective, high-quality digital health tools (15).

\section{Apps in the Primary Care Setting}

With the rapid expansion of digital health apps have come both potential benefits and challenges for primary care providers (PCPs), who must be familiar with commonly used apps to advise patients with diabetes on their use of these products. There are limited randomized controlled trials, cohort studies, or case-control studies on app-based interventions and their effects on health behaviors and outcomes. Apps are constantly being updated, and this evolution limits the ability to carry out long-term, wellconducted studies. There are also obstacles for clinicians with respect to adequate education and training, as well as issues with app accuracy, clinical validity, and quality of information. Technological challenges such as interoperability on Apple iOS or Android platforms, frequent app updates and revisions, lack of standardization of information, and variable shareability of data are additional barriers. Other concerns for HCPs include the endorsement or recommendation of specific apps by professional organizations and the quality of data and privacy security with app use.

However, there are also benefits of using apps in diabetes care. Health apps allow PCPs to communicate about glycemic data and improve health outcomes and quality of care for their patients with diabetes in ways that were not previously possible.

\section{Reimbursement}

There are financial incentives for spending time interpreting mobile app data. Interpretation of $>72$ hours of continuous glucose monitoring (CGM) data collected via mobile app or receiver can be billed monthly using Current Procedural Terminology (CPT) code 95251 (16). Since 1 January 2018, the Centers for Medicare \& Medicaid Services has allowed eligible practitioners to bill for reimbursement for time spent interpreting and collecting health data generated by patients remotely. These data must be recorded and transmitted to the provider, with a minimum of 30 minutes of time spent outside of the patient visit, and billed using CPT 99091 (17). Table 1, which summarizes details of some of the most commonly used apps for diabetes, includes information, where appropriate, on specific costs and billing codes.

\section{ADA Standards of Care App}

The ADA first published its Clinical Practice Recommendations in 1988. Now known as the Standards of Medical Care in Diabetes, these guidelines are published each January in the journal Diabetes Care and made available for free online (18). The Standards of Care is a comprehensive guide to diabetes treatment, therapeutic goals, and tools to evaluate quality of care. An abridged version of the Standards of Care for PCPs is also published annually in the journal Clinical Diabetes and made available for free online (19). 
TABLE 1 Summary of Diabetes Apps

\begin{tabular}{lcccc} 
App & Platform* & Type & Cost & Patient Benefit \\
\hline ADA SOC & Apple/Android & $\begin{array}{c}\text { Medical care } \\
\text { recommendations }\end{array}$ & Free & -
\end{tabular}

\begin{tabular}{|c|c|c|c|c|c|}
\hline $\begin{array}{l}\text { OneTouch } \\
\text { Reveal }\end{array}$ & Apple/Android & Glucose tracking & Free & $\begin{array}{l}\text { - Wireless data pairing } \\
\text { - Glucose alerts } \\
\text { - Food, medication, and } \\
\text { activity tracking }\end{array}$ & $\begin{array}{l}\text { - Data sharing } \\
\text { - HCP reports }\end{array}$ \\
\hline My Sugr & Apple/Android & Glucose tracking & $\begin{array}{l}\text { Basic: free; premium: My } \\
\text { Sugr PRO } \$ 27.99 / \text { year } \\
\text { subscription; coaching } \\
\text { plans: } \$ 19.99-\$ 399.99\end{array}$ & $\begin{array}{l}\text { - Wireless data pairing } \\
\text { - Medication and } \\
\text { carbohydrate tracking }\end{array}$ & $\begin{array}{l}\text { - HCP reports } \\
\text { - } \mathrm{A} 1 \mathrm{C} \text { prediction }\end{array}$ \\
\hline $\begin{array}{l}\text { iHealth Gluco- } \\
\text { Smart }\end{array}$ & Apple/Android & Glucose tracking & $\begin{array}{l}\text { Free; requires iHealth } \\
\text { Gluco-Monitoring System }\end{array}$ & $\begin{array}{l}\text { - Wireless data pairing } \\
\text { - Diet and activity tracking }\end{array}$ & $\begin{array}{l}\text { - Data sharing } \\
\text { - Secure Cloud data } \\
\text { storage }\end{array}$ \\
\hline One Drop & Apple/Android & Glucose tracking & $\begin{array}{l}\text { Basic: free; premium: } \\
\$ 17.99 / \text { month digital- } \\
\text { only membership; } \\
\$ 30.99-\$ 89.99 \\
\text { membership with } \\
\text { digital plus glucose } \\
\text { meter and strips }\end{array}$ & $\begin{array}{l}\text { - Wireless data pairing } \\
\text { - Diet, medication, and } \\
\text { activity tracking } \\
\text { - Real-time decision support } \\
\text { via personalized coach }\end{array}$ & - HCP reports \\
\hline Health2Sync & Apple & Glucose tracking & $\begin{array}{l}\text { Basic: free; advanced: } \\
\$ 2.99 / \text { month } \\
\text { subscription }\end{array}$ & $\begin{array}{l}\text { - Manual glucose tracking/ } \\
\text { download with smart cable } \\
\text { - Biometric tracking } \\
\text { - Food, medication, and } \\
\text { activity tracking }\end{array}$ & - HCP reports \\
\hline $\begin{array}{l}\text { Beat0 Smart/ } \\
\text { Beat0 Curv }\end{array}$ & Apple/Android & Glucose tracking & Free & $\begin{array}{l}\text { - Glucose meter connection } \\
\text { via 3.5-mm audio jack/ } \\
\text { charging port for data } \\
\text { pairing } \\
\text { - Option to connect with } \\
\text { diabetes specialists } \\
\text { - Activity tracker } \\
\text { - Link to diabetes-friendly } \\
\text { foods and products }\end{array}$ & $\begin{array}{l}\text { - HCP reports } \\
\text { - Glucose trend } \\
\text { analysis }\end{array}$ \\
\hline
\end{tabular}




\section{TABLE 1 Summary of Diabetes Apps (continued)}

\begin{tabular}{|c|c|c|c|c|c|}
\hline App & Platform* & Type & Cost & Patient Benefits & HCP Benefits \\
\hline $\begin{array}{l}\text { Dario Health } \\
\text { Diabetes } \\
\text { Management }\end{array}$ & Apple/Android & Glucose tracking & $\begin{array}{l}\$ 25-\$ 70 / \text { month } \\
\text { subscription; covered by } \\
\text { insurance for some }\end{array}$ & $\begin{array}{l}\text { - Glucose meter connection } \\
\text { via 3.5-mm audio jack/ } \\
\text { charging port for data } \\
\text { pairing } \\
\text { - Tracks carbohydrates, } \\
\text { insulin, and activity } \\
\text { - Database of } 500,000 \text { food } \\
\text { items } \\
\text { - Emergency GPS location } \\
\text { services } \\
\text { - Proven glycemic } \\
\text { improvement for } \\
\text { hyperglycemia and normal } \\
\text { glucose (80-120 mg/dL) } \\
\text { for patients with type } 2 \\
\text { diabetes }\end{array}$ & - HCP reports \\
\hline
\end{tabular}

$\begin{array}{ccl}\text { Glooko Apple/Android } & \begin{array}{c}\text { Data managementand } \\ \text { monitoring }\end{array} & \begin{array}{l}\text { Free to individuals; } \\ \text { custom pricing for } \\ \text { clinicians }\end{array}\end{array}$

- Multidevice compatibility and integration $(>100$ devices)

- Database of 500,000 food items

- Diet and activity logging
- Remote patient monitoring

- HCP reports

- Insulin pump, insulin pen, CGM, glucose meter, and smart app integration

\begin{tabular}{|c|c|c|c|c|c|}
\hline $\begin{array}{l}\text { Dexcom G5/G6 } \\
\text { CGM }\end{array}$ & Apple/Android & CGM & Free & $\begin{array}{l}\text { - Real-time alerts } \\
\text { - Severe hypoglycemia } \\
\text { prediction alert (G6 only) } \\
\text { - Rate-of-change alerts } \\
\text { - Data sharing }\end{array}$ & - \\
\hline Dexcom Follow & Apple/Android & CGM & Free & $\begin{array}{l}\text { Real-time alerts for high, } \\
\text { low, and urgent low }(<54 \\
\mathrm{mg} / \mathrm{dL}) \text { glucose }\end{array}$ & - \\
\hline
\end{tabular}




\section{TABLE 1 Summary of Diabetes Apps (continued)}

\begin{tabular}{lclc} 
App & Platform* & Type & Cost \\
\hline $\begin{array}{l}\text { FreeStyle } \\
\text { LibreLink }\end{array}$ & Apple/Android & CGM & Free
\end{tabular}

Patient Benefits

HCP Benefits

- Real-time glucose values - Remote patient updated every minute

- Painless, 1-second scan to monitoring via see glucose value and trends

- In-app reports with retrospective glucose trends and patterns, including Time in Target and Daily Patterns (AGP)

LibreView

- Standardlized AGP report with CGM metrics included in HCP reports

- Connects with HCPs and caregivers to seamlessly share glucose information

- Food, insulin, and activity logging

\begin{tabular}{lccl}
\hline LibreLinkUp & Apple/Android & CGM & \\
& & & \\
\hline $\begin{array}{l}\text { Medtronic } \\
\text { Guardian } \\
\text { Connect }\end{array}$ & $\begin{array}{c}\text { Apple/ } \\
\text { Android-under } \\
\text { development }\end{array}$ & CGM & $\begin{array}{l}\text { Free; Guardian CGM } \\
\text { prescription required } \\
\text { for use }\end{array}$ \\
\hline
\end{tabular}

- Shareable with up to 20 followers

- Notifications include current glucose and trend arrow

- Logbook of previous glucose values

- Real-time glucose data and - Data shared to HCP alerts clinic

- Predictive alerts (60 minutes)

- Data auto-uploaded to Medtronic CareLink

\begin{tabular}{|c|c|c|}
\hline ree & $\begin{array}{l}\text { - Real-time glucose data and } \\
\text { alerts } \\
\text { - Predictive alerts } \\
\text { - Temporary glucose profiles } \\
\text { and do not disturb mode } \\
\text { - Sharable with up to five } \\
\text { followers via Eversense } \\
\text { Now app }\end{array}$ & - \\
\hline ree & $\begin{array}{l}\text { - Real-time access to various } \\
\text { CGM device data via } \\
\text { personal website, smart } \\
\text { watch, or app for CGM } \\
\text { users and their followers } \\
\text { - All CGMs are compatible } \\
\text { with Nightscout }\end{array}$ & $\begin{array}{l}\text { - Remote patient } \\
\text { monitoring } \\
\text { - HCP reports } \\
\text { - CPT code } 95251 \text { for } \\
\text { reimbursement }\end{array}$ \\
\hline ree & $\begin{array}{l}\text { - Compatible with pumps, } \\
\text { CGM systems, glucose } \\
\text { meters } \\
\text { - Insulin, CGM, carbohydrate } \\
\text { data tracking with notes }\end{array}$ & $\begin{array}{l}\text { - HCP reports } \\
\text { - Secure and } \\
\text { anonymous data } \\
\text { donation for future } \\
\text { research }\end{array}$ \\
\hline
\end{tabular}

\begin{tabular}{|c|c|c|c|}
\hline SugarlQ & Apple & CGM & $\begin{array}{l}\text { Free; Guardian CGM } \\
\text { prescription required } \\
\text { for use }\end{array}$ \\
\hline
\end{tabular}

\begin{tabular}{llll}
\hline Eversense & Apple/Android & CGM & Free
\end{tabular}

$\begin{array}{lll} & & \\ & & \\ \text { CGM in } & \text { Apple/Android } & \text { CGM }\end{array}$

- IBM Watson analytics for pattern detection

- Personal insights based on retrospective data provided via text messages

Real-time glucose data and

- Temporary glucose profiles and do not disturb mode followers via Eversense CGM device data via watch, or app for CGM and their follor

- All CGMs are compatible

Compatible with pumps,

Tidepool Mobile Apple/Android CGM/multidevice data management

\section{meters}

data tracking with notes
- CPT code 95251 for reimbursement 


\section{TABLE 1 Summary of Diabetes Apps (continued)}

\begin{tabular}{|c|c|c|c|}
\hline App & Platform* & Type & Cost \\
\hline Livongo & Apple/Android & Lifestyle support & $\begin{array}{l}\$ 73-\$ 99 / \text { month } \\
\text { subscription; typically } \\
\text { provided by insurance } \\
\text { plan }\end{array}$ \\
\hline
\end{tabular}

Patient Benefits

HCP Benefits subscription; typically plan

- Real-time support from diabetes response specialists

- Health nudges: recipes, tips, and articles

- Unlimited test strip and lancet ordering via app

\begin{tabular}{|c|c|c|c|c|c|}
\hline Apple Health & Apple & Lifestyle support & Free & $\begin{array}{l}\text { - Glucose and medication/ } \\
\text { insulin tracking } \\
\text { - Laboratory value storage } \\
\text { - Apple HealthKit-linked CGM } \\
\text { and glucose meter data } \\
\text { - Personal health data } \\
\text { storage }\end{array}$ & $\begin{array}{l}\text { - Streamlined health } \\
\text { data sharing } \\
\text { - Patient portal linking } \\
\text { with affiliated health } \\
\text { care organizations }\end{array}$ \\
\hline Calorie King & Apple & Lifestyle support & Free & $\begin{array}{l}\text { - Database of } 100,000 \text { food } \\
\text { items from } 260 \text { restaurants } \\
\text { and fast-food chains }\end{array}$ & - \\
\hline Glucose Buddy & Apple & Lifestyle support & $\begin{array}{l}\text { Basic: free; advanced: } \\
\$ 59.99\end{array}$ & $\begin{array}{l}\text { - } \mathrm{A} 1 \mathrm{C} \text { and blood glucose } \\
\text { tracking } \\
\text { - Medication, weight, blood } \\
\text { pressure, and dietary } \\
\text { tracking }\end{array}$ & - \\
\hline Meal IQ & Android & Lifestyle support & $\begin{array}{l}\text { Basic: free; premium: } \\
\text { subscription TBA† }\end{array}$ & $\begin{array}{l}\text { - Customized meal planning } \\
\text { based on diet, cost, } \\
\text { ingredients, and } \\
\text { macronutrients } \\
\text { - Linked to online grocery stores }\end{array}$ & - \\
\hline Beat Diabetes & Android & Lifestyle support & Free & $\begin{array}{l}\text { - Basic education for users } \\
\text { new to diabetes } \\
\text { - Information about } \\
\text { complications and } \\
\text { treatments } \\
\text { - Modern medicine and } \\
\text { Ayurvedic practices }\end{array}$ & - \\
\hline
\end{tabular}




\begin{tabular}{|c|c|c|c|c|c|}
\hline App & Platform* & Type & Cost & Patient Benefits & HCP Benefits \\
\hline Diabetic Diet & Android & Lifestyle support & Free & $\begin{array}{l}\text { - Healthy eating guides } \\
\text { - Audio lessons for healthy } \\
\text { eating and weight loss }\end{array}$ & - \\
\hline Sugar Sense & Apple & Lifestyle support & Free & $\begin{array}{l}\text { - Glucose, insulin, } \\
\text { carbohydrate, weight, and } \\
\text { exercise tracker } \\
\text { - Step counter } \\
\text { - Estimated A1C }\end{array}$ & - \\
\hline BlueStar & Apple/Android & $\begin{array}{l}\text { Combination blood } \\
\text { glucose data } \\
\text { management and } \\
\text { lifestyle support }\end{array}$ & $\begin{array}{l}\text { Free; requires access } \\
\text { code from employer or } \\
\text { health plan }\end{array}$ & $\begin{array}{l}\text { - Artificial intelligence- } \\
\text { derived feedback } \\
\text { - Custom reports and } \\
\text { education } \\
\text { - Wireless data pairing } \\
\text { - Medication, food, sleep, } \\
\text { exercise, and blood } \\
\text { pressure tracking }\end{array}$ & $\begin{array}{l}\text { - Connected to HCP } \\
\text { team } \\
\text { - Access to diabetes } \\
\text { care and education } \\
\text { specialists } \\
\text { - Electronic medical } \\
\text { record integration }\end{array}$ \\
\hline Glucagon & Apple/Android & $\begin{array}{l}\text { Medication } \\
\text { management }\end{array}$ & Free & $\begin{array}{l}\text { - Simulation for use } \\
\text { - Audible and visual } \\
\text { instructions } \\
\text { - Glucagon kit tracker } \\
\text { - Reminder notification }\end{array}$ & - \\
\hline GoodRX & Apple/Android & $\begin{array}{l}\text { Prescription cost- } \\
\text { saving }\end{array}$ & Free & $\begin{array}{l}\text { - Comparison of drug prices } \\
\text { - Coupons for print or in-app } \\
\text { use } \\
\text { - Price tracking and alerts for } \\
\text { drugs and medical supplies }\end{array}$ & - \\
\hline RxSaver & Apple/Android & $\begin{array}{l}\text { Prescription cost- } \\
\text { saving }\end{array}$ & Free & $\begin{array}{l}\text { - Comparison of drug prices } \\
\text { - Coupons for print or in-app } \\
\text { use } \\
\text { - "My Meds" list for coupons and } \\
\text { personal prescription list }\end{array}$ & - \\
\hline
\end{tabular}

*For specific compatibility details, check listing on app websites such as the App Store or Google Play. † Subscription plan still under development. AGP, ambulatory glucose profile.

The ADA now also offers a Standards of Care app, available from the App Store and Google Play. A Web app is also available for online use (20). The app provides access to all 16 sections of the Standards of Care.

In addition, it includes interactive tools that provide easy, evidence-based decision support for HCPs. These interactive tools provide recommendations for hypertension treatment in patients with diabetes, drug class-specific information (i.e., efficacy; hypoglycemia risk; weight change effects, cardiovascular and renal effects, cost, route of administration, and other important clinical considerations), recommendations for glucose-lowering medication selection based on a patient's individual clinical characteristics, practical advice for intensifying from oral to injectable therapies, help setting A1C targets based on a patient's characteristics and preferences, guidelines for diabetes screening in asymptomatic adults, and a tool for entering patients' blood test results to help clinicians diagnose diabetes and identify prediabetes.

There is also a general information section providing quick access to the summary of the latest revisions to the Standards of Care. A comprehensive section on improving care and promoting health in certain populations also adds a tremendous amount of practical information for HCPs, including strategies for caring for patients with food insecurity, homelessness, migrant or seasonal employment, and language barriers.

Finally, the app provides a thorough review of the classification of diabetes, including type 1 diabetes, type 2 
diabetes, cystic fibrosis-related diabetes, post-transplant diabetes, monogenic diabetes syndromes (e.g., categories of maturity-onset diabetes in the young), diabetes from pancreatic disease, and gestational diabetes.

\section{Blood Glucose Meters and Glucose Tracking}

Several blood glucose meters with Bluetooth capability are available that can connect and transmit data to a smartphone app. The OneTouch Verio Flex meter synchronizes data automatically to the OneTouch Reveal mobile app, which is available from the App Store and Google Play. The app allows patients to track blood glucose averages; enter food, medication dosing, and activity data; set personalized lifestyle goals; share their data with others, including HCPs; get alerts for repeated high or low blood glucose readings; and integrate data into the Apple Health app (21).

The Accu-Chek Guide, Guide Me, and Aviva Connect meters can all be paired wirelessly with the mySugr app, also available from the App Store and Google Play. This app allows users to enter diet and medication information, provides glucose analysis and motivational feedback, shows predicted A1C, and can integrate information into the Apple Health and Google Fit apps (22).

The iHealth Smart meter can be paired with the iHealth Gluco-Smart app, available from the App Store and Google Play. Similar to the other apps, this one provides statistical glucose data, allows users to enter diet and activity information, and can export data to HCPs and family members (23).

One Drop provides a Bluetooth-enabled glucose meter that synchronizes with the One Drop mobile app, available from the App Store and Google Play. The app tracks and analyzes blood glucose data, medications, food, and activity levels. Real-time decision support is provided based on blood glucose readings, and personalized coaching is available to users. Data can be synchronized with many other health apps, including Apple Health, GoogleFit, FitBit, and Dexcom, among others (24). (See Table 1 for specific cost information.) Use of the One Drop system resulted in a $0.96 \%$ improvement in A1C levels among active users of both the app and a coaching program during 3 months in 93 patients with type 2 diabetes (25).

Other apps allow patients to enter diabetes health information manually or connect to glucose meters via audio jacks and charging ports but do not connect wirelessly to meters. Health2Sync is an app that allows patients to input information such as blood glucose and blood pressure readings, daily activities (i.e., food, exercise, and medications), and weight (26). The app then provides comprehensive statistical glucose information and blood pressure and weight trends. The app is available from the App Store and Google Play.

The BeatO SMART (for iPhone and Android) and BeatO Curv (for Android only) meters connect to smartphones via the $3.5 \mathrm{~mm}$ audio jack or charging port. The data are then synchronized to the BeatO app available from the App Store and Google Play. The app provides glucose trends and statistics, connects users with in-house specialists, tracks fitness levels, and provides a digital store for diabetes-friendly food products (27). Patients' data can also be shared with family, friends, and HCPs.

Dario Health provides a meter that connects to smartphones via charging ports and synchronizes with the Dario Smart Diabetes Management app that is available on the App Store and Google Play. This diabetes management system requires a subscription, some portion of which may be covered by insurance. (See Table 1 for specific cost information.) The app records and tracks blood glucose levels, carbohydrate intake, insulin and medication dosing, and physical activity. It also provides a 500,000-item food library and provides global positioning system (GPS) location identification in the event of a diabetic emergency (28). Data can be shared with HCPs and others. The Dario system showed a reduction in high blood glucose events (180-400 mg/dL) by $19.3 \%$ (from 28.4 to $22.9 \%$ ) and an increase in normal glucose readings $(80-120 \mathrm{mg} / \mathrm{dL}$ ) by $11.3 \%$ (from 25.6 to $28.5 \%$ ) with use of the app during 2017 in 17,156 people with type 2 diabetes (29).

Glooko is a diabetes data management software platform that is compatible with roughly 100 different diabetes devices, including glucose meters, insulin pumps, CGM systems, fitness apps, and smart insulin pens. Patients can download the Glooko Mobile app to a smartphone from the App Store or Google Play. They can then synchronize or upload devices to the mobile app to see data from multiple diabetes devices in one place. They can log food and activity data, and a 500,000-item food database is included. Patients can export reports to their HCP (30). In HCP offices, compatible devices can be uploaded to a computer (PC or Mac platform) using a synchronizing infrared or USB cable and Glooko Uploader software.

Many of these glucose-reporting apps and Web-based reporting systems allow patients to export glucose reports to their HCP or download reports from websites as PDF files that can then be incorporated into most commonly used electronic medical record (EMR) systems. This feature enables HCPs to look back with patients at 
previous glucose statistics to assess progress and set ongoing glycemic targets and other therapeutic goals.

\section{CGM Apps}

Dexcom CGM mobile apps record interstitial glucose data every 5 minutes and allow users to set customizable alerts and share their data by inviting others to use Dexcom Follow to remotely track their glucose. HCPs can engage patients' family members and caregivers by teaching CGM users about these Follow features. Both the Dexcom CGM app and Dexcom Follow are also available for compatible smartwatches. Dexcom offers separate apps for its G6, G5, and G4 Platinum CGM systems, and are all available from the App Store and Google Play.

Dexcom Clarity is an app for Dexcom CGM users that allows them to review their glucose trends and patterns in interactive reports that are available to share with their health care team either by using a "share code" or by downloading and sending reports via e-mail. Data from each user are continuously and automatically uploaded to Dexcom Clarity from the Dexcom CGM app, and the Clarity app is compatible with all Dexcom CGM systems. The reports provide clinically relevant statistics with suggestions for possible changes for both patients and HCPs. Reports can be viewed, saved, and printed for clinic use and CGM interpretation is billable (using CPT code 95251) under private insurers and Medicare. The Clarity app sends users a weekly summary with glucometric data, including average glucose, time in range, glycemic patterns, and trends. Patients can also quickly access their data to view their average, time above range, time below range, hypoglycemia risk, and estimated A1C (called the "glucose management indicator"). They can add additional personal data such as information on exercise, carbohydrates consumed, illness, alcohol intake, stress, or menstrual cycle (31).

The FreeStyle Libre 14-day system offers a mobile app called LibreLink. This app allows users to scan their sensor using near-field communication (NFC) to wirelessly transmit data to NFC-capable smartphones for blood glucose readings up to the past 8 hours as well as trend arrows. LibreLink also allows users to track their food, insulin, exercise, and other events. Users access their data on the ambulatory glucose profile report to view their average glucose, time in range, time above range, time below range, glucose management indicator, and active CGM time to self-adjust insulin therapy. FreeStyle Libre LinkUp is an app for up to 20 family members or friends of FreeStyle Libre users to share sensor-recorded readings from the CGM user. It remotely sends notifications with current glucose and trend arrow and creates a logbook of previous glucose levels (32).

Medtronic's Guardian Connect app displays current glucose with a trend arrow along with event markers and glucose history. There are real-time alerts for high or low glucose with predictive alerts up to 60 minutes in advance. Data are automatically uploaded to Medtronic CareLink Connect to be shared with HCPs. This app offers automatic text message alerts that allows patients to share their CGM alerts with up to five care partners. SugarIQ is a separate associated app that uses IBM Watson analytics for detecting patterns and provides real-time personalized insights (33). This app allows Guardian Connect CGM users to add meal choices. These features cannot be used for patients using the Medtronic 670G system; they are only available to patients using Medtronic CGM only.

The Eversense app displays glucose sensor data from the Senseonics Eversense implanted CGM (implanted for up to 90 days) every 5 minutes, along with rate of change arrows and real-time and predictive alerts. Temporary glucose profiles and a do-not-disturb mode are available within the app. Up to five friends or family members may receive these data remotely with Eversense NOW (34).

CGM in the Cloud, also known as Nightscout, is a do-ityourself (DIY) open-source app that allows for real-time access to CGM data via a personal website using Dexcom, Medtronic, or FreeStyle Libre CGM systems. These CGM systems are paired to Nightscout and allow any Webconnected device to display and view sensor glucose data (35).

Tidepool Mobile is an open-source mobile app supported by public foundations, including the Juvenile Diabetes Research Foundation, the Goldsmith Foundation, and the Leona M. and Harry B. Helmsley Charitable Trust. It allows users to upload data from their insulin pump, CGM system, and glucose meter in Tidepool Uploader at home on Mac or PC platforms or in the clinic. Users may add context to track daily events such as meals and exercise, as well as personal notes from their phone, in a digital diary. Tidepool Mobile may be connected to Apple Health for continuous data synchronization of CGM with other health data. This platform prompts users to voluntarily donate their anonymized data and demographics securely to help device makers and researchers develop new diabetes devices (36).

\section{Lifestyle Apps}

The Livongo mobile app monitors blood glucose by linking to its associated meter to provide personalized insight into 
glucose patterns and offers real-time support and expert coaching from diabetes response specialists via phone call or text message. Its reports are shareable with HCPs and caregivers. The app includes "health nudges" such as recipes, articles, and tips for improving glucose control. It can also store blood pressure readings and steps walked and allows users to order unlimited test strips and lancets directly from the app at no additional cost to patients. This service is provided primarily by employers and contracted through insurance plans, but it also sells monthly subscriptions to individuals (37). (See Table 1 for specific cost information.)

The Apple Health app comes pre-downloaded on iPhones and other Apple devices and integrates data from the user's iPhone, Apple Watch, iPad, and thirdparty apps. Apple device users can grant it permission to read and write data types to HealthKit, which allows for tracking carbohydrate intake, insulin use, blood glucose levels, and previous laboratory test results such as A1C. HealthKit has the capability of linking with many glucose meters and CGM systems to store and track glucose information over time, along with other personal health data. The app streamlines data-sharing between patients and HCPs. Users can link Apple Health to securely access their patient portal at affiliated health care organizations (38).

MyFitnessPal gives users access to its database of 11 million foods, allowing them to track nutrients by entering their own recipes, reviewing restaurant menu logs, or using a barcode scanner for packaged foods. They can customize goals for weight and water intake, track exercise from other mobile apps, and connect to a social network of users for community support (39).

The producers of the popular nutrition book Calorie King also offer a food database app by the same name that contains $>100,000$ foods from $>260$ restaurants and fastfood chains (40). Figwee is a food visualization app that helps users determine macronutrient content in their meals using the Figwee food library. Users match their food to the visual portion tracker for information about calories, fat, carbohydrates, protein, and micronutrients (41).

The Glucose Buddy diabetes management app has features to record and track A1C, blood glucose, medications, exercise, blood pressure, and weight, as well as a carbohydrate food database. Meal IQ helps people with diabetes understand how certain foods affect blood glucose. A premium version is available with advanced options and access to other health, nutrition, and exercise apps made by developer Azumio (42). (See Table 1 for specific cost information.) The Diabetes Connect app syncs glucose data from multiple devices into standard glucose statistics. Users can input data on insulin doses, blood glucose, medications, exercise, moods, vital signs, and notes into the app (43). The Diabetes $\mathrm{M}$ app has a bolus dose calculator that can be used with an insulin pump or multiple daily injection insulin regimen. Its logbook, food database, and basal insulin tracker can be used to create detailed charts with reports that can be shared with HCPs (44).

Beat Diabetes is an Android-only app geared toward people with newly diagnosed diabetes. It provides information about managing blood glucose, facts about diabetes complications, and treatment strategies involving modern medicine and Ayurvedic practices. It also contains lists of best and worst foods for diabetes and recommends a diet based on the American Heart Association diet (45).

Information on healthy eating and weight loss for people with diabetes can also be found on the Diabetic Diet mobile app. It may be useful for family members of people with diabetes, offering a straightforward and instructive crash course via audio lessons and healthy eating guides (46). The Sugar Sense mobile app records blood glucose, insulin, carbohydrates, weight, and exercise and also estimates A1C based on these data. It uses a step counter and a nutrition log to provide more comprehensive health data (47).

\section{Combined Blood Glucose and Lifestyle App}

The BlueStar app by Welldoc, available from the App Store and Google Play, combines data and information on blood glucose, blood pressure, medication dosing, food, exercise, and sleep. The app tracks and analyzes users' information using artificial intelligence-driven algorithms. Messages from the app health team become more individualized for each user over time and are designed to prompt real-time action. On-demand diabetes education is also available to users. The app is integrated with $>300$ other apps, devices, and EMR systems (48). Users can only get the app by obtaining a code from their participating employer or health plan and entering the code into the app.

\section{Glucagon App}

Eli Lilly released its glucagon mobile app for use on Apple devices in September 2012 and on Android devices in July 2015. This app was designed for use by insulin users and their caregivers, as well as HCPs. It is a tool that teaches glucagon injection technique, with a step-by-step, 
interactive audiovisual tutorial featuring a simulation to practice glucagon administration. The app allows for reminders to users to repeat the practice and preparation for glucagon use. Users can enter their glucagon kit expiration date and location of kit and get reminders for reordering. The app also contains drug safety information and indications for glucagon use, as well as a link to full prescribing information for HCPs. The app was last updated in July 2018 (49).

\section{Prescription Cost-Saving Apps}

The price of insulin for patients and health plans doubled between 2012 and 2016, from $\$ 2,864$ to $\$ 5,705$, according to a report from the nonprofit Health Care Cost Institute (50). Many patients with diabetes have looked for ways to reduce costs not only of insulin, but also of noninsulin diabetes drugs, glucagon, and glucose test strips. Several commonly used prescription cost-saving apps have helped patients save significantly on their medications and related costs. GoodRx and RxSaver are two popular ones.

The GoodRx app is the number- 1 free medical app available from the App Store and Google Play (51). It allows users to search for drugs and supplies and compare prices at $>70,000$ U.S. pharmacies. The app constantly gathers current prices and available discounts and provides users with anticipated costs from local pharmacies. GoodRx coupons can save users up to $80 \%$ on prescription costs and can be printed from the GoodRx website or displayed to the pharmacy via the mobile app. The average GoodRx customer saves $\$ 355 /$ year on prescription costs (52). Patients can also track prices and get automatic alerts on potential savings for their specific drugs and supplies.

The RxSaver app by RetailMeNot is another popular prescription cost-saving app. It functions similarly to GoodRx in that it allows users to search by drug name and compare prices at various pharmacies near them. The app then provides a coupon for prescriptions offering up to $80 \%$ savings. Users can print coupons or show them to the pharmacy via the mobile app. Patients can save their prescription details in the "My Meds" section, making it easier to access coupons and keep an accurate personal drug list (53).

\section{DIY Automated Insulin Delivery Apps}

Some patients have built their own DIY apps for sensoraugmented pump therapy. These apps, such as Loop, OpenAPS/Nightscout, and AndroidAPS, work with an insulin pump or pod and real-time CGM system using a controller and an algorithm to automate insulin delivery
$(54,55)$. Detailed information for the required components and instructions for building and using these apps are available on their respective websites.

Although these automated systems do not currently have FDA approval, there are ongoing efforts in progress to get them, and their apps, approved. The FDA has safety concerns about these apps being used by hackers to interfere with insulin delivery, although there is little information to substantiate this claim.

Consumer demands for mobile phone control of insulin delivery devices continue to increase (56). In 2018, the Diabetes Technology Society developed a consensus for cybersecurity and new industry standards known as DTMoST (Diabetes Technology Society Mobile Platform Controlling a Diabetes Device Security and Safety Standard) to promote the safe control of diabetes devices via mobile apps. The DTMoST addresses concerns about malicious hacking and interruptions in device connectivity (57).

\section{Conclusion}

Mobile apps increase the accessibility of data for HCPs because patients may access data from their smartphone even if they do not have their blood glucose meter with them during clinic visits. New connected diabetes tools such as app-enabled insulin pumps, app-enabled CGM systems, and smart insulin pens continue to become available. The diabetes app space will thus continue to change and develop with frequent updates and new products. Apps will become more customizable with incorporation of machine-based algorithms to provide customized treatment recommendations and remote health coaching.

\section{FUNDING}

The articles in this special-topic issue of Clinical Diabetes were supported by unrestricted educational grants to the American Diabetes Association from Abbott Diabetes Care and Dexcom.

\section{DUALITY OF INTEREST}

J.J.C. is on speaker's bureaus for Dexcom and Eli Lilly. No other potential conflicts of interest relevant to this article were reported.

\section{AUTHOR CONTRIBUTIONS}

Both authors researched the data and wrote and edited the manuscript. K.D.-D. is the guarantor of this work and, as such, accepts responsibility for the integrity of the manuscript and ensures that all statements in the manuscript are true to her knowledge. 


\section{REFERENCES}

1. Statista. Number of smartphone users worldwide from 2016 to 2021. Available from https://www.statista.com/statistics/ 330695/number-of-smartphone-users-worldwide/. Accessed 1 April 2020

2. Hood M, Wilson R, Corsica J, Bradley L, Chirinos D, Vivo A. What do we know about mobile applications for diabetes selfmanagement? A review of reviews. J Behav Med 2016;39:981-994

3. Business of Apps. App download and usage statistics 2019. Available from https://www.businessofapps.com/data/appstatistics/. Accessed 29 March 2020

4. Annie A. Report: the state of mobile 2020. Available from https://www.appannie.com/en/go/state-of-mobile-2020/.

Accessed 29 March 2020

5. Statista. Number of mHealth apps available in the Apple App Store from 1st quarter 2015 to 3rd quarter 2019. Available from https://www.statista.com/statistics/779910/health-apps-

available-ios-worldwide/. Accessed 30 March 2020

6. Statista. Number of mHealth apps available at Google Play from 1st quarter 2015 to 3rd quarter 2019. Available from https:// www.statista.com/statistics/779919/health-apps-availablegoogle-play-worldwide/. Accessed 30 March 2020

7. Istepanian RSH, Laxminarayan S, Pattichis CS, Eds. M-Health: Emerging Mobile Health Systems. Boston, MA, Springer, 2006

8. World Health Organization. mHealth: New horizons for health through mobile technologies: based on the findings of the second global survey on eHealth. Available from www.who.int/goe/ publications/goe_mhealth_web.pdf. Accessed 31 March 2020

9. Fleming GA, Petrie JR, Bergenstal RM, Holl RW, Peters AL, Heinemann L. Diabetes digital app technology: benefits, challenges, and recommendations: a consensus report by the European Association for the Study of Diabetes (EASD) and the American Diabetes Association (ADA) Diabetes Technology Working Group. Diabetes Care 2020;43:250-260

10. Association of Diabetes Care \& Education Specialists. It's here! DANA app review. Available from https://www. diabeteseducator.org/news/perspectives/aade-blog-details/ molly-mcelwee-malloy/2018/02/05/it's-here-dana-app-review. Accessed 16 April 2020

11. European Commission. Transformation of health and care in the digital single market. Available from https://ec.europa.eu/digitalsingle-market/en/policies/ehealth. Accessed 19 September 2018

12. Van Norman GA. Drugs and devices: comparison of European and U.S. approval processes. JACC Basic Transl Sci 2016;1:399-412

13. U.S. Food and Drug Administration. Policy for device software functions and mobile medical applications: guidance for industry and Food and Drug Administration staff. Available from https:// www.fda.gov/media/80958/download. Accessed 6 April 2020

14. Kvedar JC, Fogel AL, Elenko E, Zohar D. Digital medicine's march on chronic disease. Nat Biotechnol 2016;34:239-246

15. U.S. Food and Drug Administration. Submitting documents using real-world data and real-world evidence to FDA for drugs and biologics: guidance for industry. Available from https:// www.fda.gov/media/124795/download. Accessed 13 June 2019
16. American Association of Clinical Endocrinologists. CPT codes 95249 , 95250, and 95251. Available from https://pro.aace.com/practicemanagement/cpt-codes-95249-95250-and-95251. Accessed 15 April 2020

17. Care Innovations. CMS unbundles CPT code 99091 , increasing reimbursement allowance for remote care. Available from https:// news.careinnovations.com/blog/cms-unbundles-cpt-code-99091increasing-reimbursement-allowance-for-remote-care. Accessed 20 March 2020

18. American Diabetes Association. Introduction: Standards of Medical Care in Diabetes-2020. Diabetes Care 2020;43(Suppl. 1):S1-S2

19. American Diabetes Association. Standards of Medical Care in Diabetes-2020 abridged for primary care providers. Clin Diabetes 2020;38:10-38

20. American Diabetes Association. ADA Standards of Care app. Available from https://adastandardsapp.diabetes.org/ada-webapp/home/. Accessed 11 April 2020

21. LifeScan. OneTouch Reveal mobile and web apps. Available from https://www.onetouch.com/products/softwares-andapps/one-touch-reveal-mobile-and-web-app. Accessed 12 April 2020

22. Roche Diabetes Care. mySugr app. Available from https:// www.accu-chek.com/apps-and-software/mysugr-app.

Accessed 12 April 2020

23. iHealth Labs. iHealth Smart Gluco-Monitoring System. Available from https://ihealthlabs.com/glucometer/wirelesssmart-gluco-monitoring-system/. Accessed 12 April 2020

24. Informed Data Systems. One Drop mobile app. Available from https://onedrop.today/pages/mobile-app. Accessed 20 September 2020

25. Kumar S, Moseson H, Uppal J, Juusola JL. A diabetes mobile app with in-app coaching from a certified diabetes educator reduces A1c for individuals with type 2 diabetes. Diabetes Educ $2018 ; 44: 226-236$

26. Health2Sync. Health2Sync app. Available from https:// www.health2sync.com/patients. Accessed 13 April 2020

27. Health Arx Technologies. BeatO. Available from https:// beatoapp.com/. Accessed 13 April 2020

28. Health D. Dario Blood Glucose Monitoring System. Available from https://www.dariohealth.com/solutions/my-dario/.

Accessed 15 April 2020

29. Hershcovitz Y, Feninger E, Dar S. T2D users of a digital diabetes management system experience a shift from greater than $180 \mathrm{mg} / \mathrm{dL}$ to normal glucose levels with sustainable results [Abstract]. Diabetes 2018;67(Suppl. 1):76-LB

30. Glooko. Glooko mobile app. Available from https:// www.glooko.com/people-with-diabetes/. Accessed 18 April 2020

31. Dexcom. Data analysis. Available from https://

provider.dexcom.com/products/data-analysis. Accessed 16 April 2020

32. Abbott. FreeStyle LibreLink. Available from https:// www.freestylelibre.us/system-overview/continous-glucosemonitor-app.html?gclid=CjwKCAjwqdn1BRBREiwAEbZc R8QGxAejleQ0lLMtXhhbCu_TVpMLAHVhTEte4AWtEn3HRTAK83nFBoCbsMQAvD_BwE. Accessed 15 April 2020 
33. Medtronic Diabetes. Guardian Connect system support. Available from https://uww.medtronicdiabetes.com/customersupport/guardian-connect-system-support. Accessed 5 May 2020

34. Senseonics. Eversense mobile app. Available from https:// www.eversensediabetes.com/mobile-app. Accessed 5 May 2020

35. The Nightscout Project. Welcome to Nightscout. Available from http://www.nightscout.info/. Accessed 16 April 2020

36. Tidepool Project. Tidepool app. Available from https:// www.tidepool.org/users. Accessed 5 May 2020

37. Livongo. A unique experience for every member. Available from https://www.livongo.com/program.html. Accessed 15 April 2020

38. Apple. Healthcare-health records. Available from https:// uww.apple.com/healthcare/health-records/. Accessed 15 April 2020

39. Under Armour. MyFitnessPal app. Available from https:// www.myfitnesspal.com/. Accessed 5 May 2020

40. Calorie King. Calorie King app. Available from https:// www.calorieking.com/us/en/. Accessed 5 May 2020

41. Figwee. Figwee app. Available from http://figwee.com/learnmore/. Accessed 9 May 2020

42. Azumio. Glucose Buddy app. Available from https:// www.glucosebuddy.com/. Accessed 9 May 2020

43. Diabetes Connect. Diabetes Connect app. Available from http://www.diabetesconnect.de/en/. Accessed 5 May 2020

44. Sirma Medical Systems. Diabetes M app. Available from https://www.diabetes-m.com/. Accessed 6 May 2020

45. Beat Diabetes. Beat Diabetes app. Available from https:// beatdiabetesapp.in/. Accessed 6 May 2020

46. Diabetic Diet app. Available from https://play.google.com/ store/apps/details?id=com.gatoapps.diabeticdiet\&hl=en_US. Accessed on 20 September 2020

47. Sugar Sense. Available from https://diabetespedia.com/ mobile-apps/sugar-sense/. Accessed 20 September 2020
48. Welldoc. BlueStar app. Available from https:// www.welldoc.com/product/. Accessed 20 May 2020

49. Eli Lilly and Company. Lilly Diabetes launches mobile application for those who support people with type 1 diabetes. Available from https://investor.lilly.com/news-releases/newsrelease-details/lilly-diabetes-launches-mobile-applicationthose-who-support. Accessed 16 April 2020

50. Health Cost Institute. Reuters: U.S. insulin costs per patient nearly doubled from 2012 to 2016: study. Available from https:// healthcostinstitute.org/in-the-news/2019-02-06-15-19-58.

Accessed 18 April 2020

51. GoodRx. GoodRx mobile app. Available from https:// www.goodrx.com/mobile. Accessed 19 April 2020

52. GoodRx. How GoodRx works. Available from https:// www.goodrx.com/how-goodrx-works. Accessed 19 April 2020

53. RetailMeNot. RxSaver app. Available from https:// rxsaver.retailmenot.com/pharmacy-apps/. Accessed 22 April 2020

54. Lewis D. History and perspective on DIY closed looping. J Diabetes Sci Technol 2019;13:790-793

55. Hng TM, Burren D. Appearance of do-it-yourself closedloop systems to manage type 1 diabetes. Intern Med J 2018;48: 1400-1404

56. Petruzelkova L, Soupal J, Plasova V, et al. Excellent glycemic control maintained by open-source hybrid closed-loop AndroidAPS during and after sustained physical activity. Diabetes Technol Ther 2018;20:744-750

57. Diabetes Technology Society. DTMoST: Diabetes Technology Society mobile platform controlling a diabetes device security and safety standard. Available from https:// www.diabetestechnology.org/dtmost.shtml. Accessed 5 May 2020 